\title{
La sagrada obsesión por capturar al personaje. Un encuentro con el fotógrafo peruano Herman Schwarz
}

\section{THE SACRED OBSESSION OF CAPTURING THE CHARACTER. AN ENCOUNTER WITH THE PERUVIAN PHOTOGRAPHER HERMAN SCHWARZ}

Alonso Rabí do Carmo

Universidad de Lima

\section{RESUMEN}

Esta entrevista ofrece a los lectores la mirada del artista sobre su propio trabajo. Esto abre no solamente una nueva perspectiva de análisis crítico del discurso o el objeto artístico (existe una marcada tendencia crítica a no considerar las palabras del artista), sino que, además, complementa otras miradas o lecturas posibles. En este caso, se trata de Herman Schwarz, un notable fotógrafo peruano que ha transitado con solvencia distintos campos durante los últimos cuarenta años, que van desde la fotografía documental hasta la poética del retrato, pasando por el uso de la imagen como herramienta social y documental. La voz del fotógrafo es la guía que irá descubriendo los pilares de su vocación y explicando al detalle las características de su discurso.

PALABRAS CLAVE: fotografía, sociedad, discurso artístico, vocación, imagen documental

\section{ABSTRACT}

This interview offers to our readers the artist's eye on his own work. This opens not only a new perspective of critical analysis of the discourse or the artistic object (there is a marked critical tendency not to consider the words of the artist), but also complements other possible approaches or readings. In this case, it is Herman Schwarz, a notable Peruvian photographer, who has worked with solvency on different fields during the last forty years, ranging from documentary photography to the poetics of the portrait, through the use of the image as a social and documentary tool. The voice of the photographer is the guide who will discover the pillars of his vocation and explain in detail the characteristics of his speech.

KEYWORDS: photography, society, artistic discourse, vocation, documentary image 
La fotografía peruana tiene una importante tradición y, en el corpus de sus imágenes, las tomadas por Herman Schwarz (Lima, 1954) ocupan un lugar indiscutible. La fotografía de Schwarz tiende a la naturalidad en la representación e invoca en los gestos de sus retratos un instante crucial que permite entender a cada personaje. La hondura de su mirada es, pues, una de sus características centrales. ¿Y qué ha logrado con eso? Construir un estilo, un universo personal, es cierto, pero que no es ajeno a los vaivenes sociales.

De este modo, la intimidad de un personaje captada en ese momento invisible al ojo continuo también tiene que decirnos algunas cosas sobre el entorno, porque Schwarz ha hecho suyo un virtuosismo que no descuida el realismo y, a la vez, no reniega del artificio para lograr sus impecables imágenes. Imaginación, impulso artístico y ánimo documental son los tres vectores que convergen en su arte.

Las razones de esa convergencia pueden ser múltiples, pero hay una que no debemos descuidar ni mirar de soslayo: el hecho de que Schwarz haya dedicado varios años de su experiencia a la edición fotográfica periodística, lo que de por sí revela un contacto cotidiano con el mundo fáctico, ese mundo en el que la experiencia social e histórica cobran concreción.

El reconocido crítico de arte y curador Augusto del Valle confirma esta lectura, en un texto escrito para el libro Al ras del suelo. La imagen documental (2012), que contiene una muestra antológica del trabajo de Schwarz, en el cual practica un riguroso examen de las diversas etapas y motivos presentes en el universo del fotógrafo. En la conclusión de su artículo, se dice que hay un recorrido en el conjunto de las imágenes

que va de lo específico del acontecimiento hacia otro aspecto de lo real y deja asomar cierto potencial alegórico de la imagen. Con esto último, la dialéctica entre el documentalismo gráfico y el documento a secas se revela como una fuerza de impulso. Por otro lado, la mirada que recoge una poética proveniente de la pintura reaparece. (p. 28)

Dialogar con un creador es una oportunidad de conocer su sensibilidad, de explorar en los resortes que motivan su vocación y que son los cimientos de su propia poética. Lo que sigue es un diálogo con Herman Schwarz, en el que el fotógrafo explica (y se explica) los pormenores de su trabajo.

¿Podrías recordar tus inicios en la fotografía? ¿Cómo descubriste tu vocación? ¿Hubo personas decisivas en ella?

La primera vez que sentí la necesidad de registrar algo con la fotografía fue durante un concierto de rock. Yo estaba estudiando arte en Misuri desde 1973 y George Harrison era el primer Beatle que hacía un tour en los Estados Unidos tras el rompimiento del grupo en 1969, cuya última presentación había sido en 1966. George Harrison tocó en el Arena de Saint Louis el 20 de noviembre de 1974. 
Recuerdo que estábamos en el mezanine, pegados a la baranda sobre el escenario, mientras su telonero Ravi Shankar en la cítara hacía su demasiado larga performance; de pronto, George salió detrás de las cortinas a mirar al público y alzó la mirada hacia nosotros. Ahí pensé: "Cómo no tengo una cámara, carajo". Tal vez la idea se me cruzó porque una de las amigas que nos acompañó tenía una cámara, pero que no estaba cerca en ese momento.

Esa Navidad, me regalaron un vale de una tienda fotográfica y -con algo más- pude comprarme mi primer equipo réflex, una Canon TLb.

\section{Buena parte de tu carrera se ha desarrollado en el ámbito periodístico. ¿Notas alguna disputa, alguna zona no resuelta entre la fotografía periodística y la artística? Muchas veces oí decir en los diarios en que trabajé que los fotoperiodistas tenían que renunciar a lo estético. ¿Cómo ves esto?}

En realidad, cuando comencé a colaborar en los medios, a fines de los setenta, no existía esa preocupación. Primero, porque la diagramación, el arte final, el papel periódico y la calidad de la impresión no eran de mucha calidad. El espacio que se le daba a la foto era mínimo y lo que importaba era que contara algo de lo que trataba la nota informativa. Se usaba mucho archivo y se pirateaba de lo lindo: era lo que comúnmente se hacía.

Mientras que la fotografía te diera la información necesaria, lo artístico era complementario, un plus, nadie espera nada especial, sobre todo en esos años cuando el común de los reporteros gráficos eran formados en los mismos medios de prensa. La cualidad máxima de una foto periodística era su carácter de primicia, haber captado el momento noticioso del día. Podría ser el momento del gol, el gesto del político que da la noticia, el accidente, el muerto, el incendio. Cuando empecé a trabajar para algunos medios de prensa, tener una cámara era suficiente.

En los medios era suficiente ser pariente o ahijado del jefe de fotografía; se comenzaba desde abajo: cargar rollos, secar negativos y fotos. De ahí, a revelar y archivar. Luego, a copiar lo que los editores o el director del medio selecciona. Todo es parte del entrenamiento práctico empírico, porque al día siguiente del trabajo de laboratorio veías en el diario impreso las mejores fotos.

En un medio periodístico existen las notas de actualidad y las inactuales, que son las que te permitían más creatividad. En cambio, para las noticias de actualidad, muchas veces importan más las circunstancias del momento que la calidad artística de la imagen. Por ejemplo, consigues hacerle un retrato espectacular a Borges, un claroscuro dramático maravilloso, pero tienes otra saludando al presidente de la República, no tan buena; bueno, esa se publica: es más noticiosa. 
Hoy la cosa ha cambiado. Creo que se permiten más licencias y se arriesga un poco más en aras de la originalidad y explotando "las bondades" del Photoshop.

\section{¿A qué fotógrafos considerarías como tus maestros, de quienes aprendiste más?}

Yo me considero un autodidacta, porque eran pocos los colegas dispuestos a darte consejos, a menos que sean para hacerte fallar la toma o malograr tu rollo durante el revelado: eso era lo más común. La filosofía era hacerte pagar "derecho a piso", sobre todo si no eras un recomendado del jefe de fotografía.

Los fotógrafos que destacaban en esos años eran sin duda los de Caretas. Sobresalía el Chino Domínguez en la parte política, que siempre estaba en el momento preciso; Víctor Manrique, en los retratos. Aunque pocos gozaban del reconocimiento público, porque no solían ponerles créditos a las fotos. La estrategia empresarial parecía ser la de mantener a los reporteros gráficos en el anonimato para que no se hagan conocidos y sean tentados por otros medios y, de paso, mantienes los sueldos bajos.

En la parte cultural de Caretas, destacaban los retratos de Alicia Benavides, que me traían a la memoria las fotos de Baldomero Pestana, que había visto publicados años atrás en la revista Fanal de la International Petroleum Company. No había muchos lugares donde ver buenas fotografías. A mi casa llegaban por suscripción la revista Life en español, Fanal de la IPC y muchas revistas médicas de propaganda farmacéutica para un hermano mayor que había emigrado años antes, pero seguían llegando y andaban por ahí mostrando las interioridades del cuerpo humano a quien se atreviera a hojearlas.

A fines de los setenta también llamó mi atención el grupo Interfoto, que trabajaba en la revista Amauta, publicación del partido que lideraba Javier Diez Canseco, Vanguardia Revolucionaria. No los conocía aún, pero lo integraban Gilberto Hume, Carmen Barrantes, Ernesto Jiménez, entre otros.

\section{¿Quiénes constituyen para ti los hitos más importantes en la tradición de la fotografía peruana?}

Los enumero: la tesis del profesor Keith McElroy sobre la fotografía peruana del siglo XIX, en 1977, y la publicación -como libro- de parte de ella en el mismo año; la puesta en valor del archivo de Martín Chambi en 1978 por Edward Ranney y la Fundación Earthwatch; la Galería Secuencia de Fernando La Rosa; la compra del Archivo Courret por la BNP, bajo la dirección de Juan Mejía Baca en 1986 y su inventariado por el equipo del Consejo Peruano de Fotografía; el Primer Coloquio de Fotografía Peruana en la Universidad de Lima en 1989, organizado por Jorge Deustua, y la exposición y libro del MALI: La recuperación de la memoria: Perú, 1842-1942 en el 2001. 


\section{¿Y en la tradición latinoamericana?}

Los coloquios internacionales de fotografía en México. Las publicaciones argentinas de La Azotea de Sara Facio y Alicia D’Amico. La exposición internacional de Erika Billeter, donde aparecen por primera vez los maestros europeos, norteamericanos y latinoamericanos (1980).

¿Tu trabajo más personal como fotógrafo se sustenta en algún bagaje teórico? ¿Cuáles serían, en todo caso, los resortes menos evidentes, los secretos de tu trabajo fotográfico más personal?

La fotografía como documento social de Gisèle Freund se publicó en 1936, pero es de una actualidad que sigue vigente. La fotografía sigue siendo, para mí, esa cámara oscura que detiene el tiempo "sin la intervención de la mano del hombre", con una fidelidad que es sorprendente y eterna.

La fotografía aparece como resultado de una prolongada búsqueda: hacer permanente la imagen que se formaba dentro de la cámara obscura. Por otro lado, el propósito del arte siempre fue imitar a la naturaleza al detalle. Al aparecer la fotografía produce una revolución en las artes plásticas, pues les quita a los pintores esa necesidad primordial de imitar a la naturaleza y copiarla tal cual, y nace el impresionismo, cuya generación no se sentía con la obligación de copiar la naturaleza, sino de interpretarla.

Que otros traten de negar esa cualidad intrínseca diciendo que "toda fotografía es mentira" no me mueve una ceja; tratan de envolver "toda" la fotografía en un mismo paquete, como si la fotografía documental y periodística tuviera algo que ver con el trabajo de artistas que utilizan la cámara fotográfica como herramienta para realizar sus creaciones.

Trabajo en la línea de los fotógrafos del siglo xx, tratando de que mi trabajo refleje mi tiempo.

\section{¿Qué singularidad o rasgo exclusivo ofrece la fotografía como arte y como medio que nos permite conocer el entorno en que vivimos?}

Hay artistas que son capaces de universalizar su mundo interior y otros que tienen un lenguaje tan personal que solo permiten ver un proceso particular, que por supuesto puede ser genial; quién sabe su reconocimiento sea compartido por un entorno muy cerrado.

Hoy se le llama fotografía a cualquier imagen producida por una máquina reproductora, no necesariamente una cámara oscura y no necesariamente la imagen reproducida ha sido originalmente creada por el que la está reproduciendo. La apropiación de imágenes ajenas es parte de las nuevas corrientes del arte contemporáneo. 


\section{¿Crees que la fotografía en el Perú es un arte lo suficientemente valorado? No contamos con un museo especializado, por ejemplo.}

Los principales críticos y curadores parecen estar más en el rol de ser el nexo entre la producción de arte y el mercado: señalando quiénes son los que les parecen importantes y quiénes no. Una crítica que favorece a un grupo pequeño de artistas y también curadores que viven del discurso conceptual.

\section{¿Cómo juzgarías el desempeño de la crítica de fotografía en el Perú? ¿Quiénes en ese campo son para ti voces autorizadas?}

El problema de la crítica en el Perú es que generalmente son los mismos curadores de las muestras los que publican sus puntos de vista en los medios, y eso los convierte en juez y parte. Y la verdad es que pocas veces las entiendo, el lenguaje es tan especializado, $\tan$ críptico que solo los otros curadores entienden y se aplauden mutuamente. Entonces, viene lo lógico: entre ellos se seleccionan y se invitan y nadie les hace sombra. Aquí estamos entre dos corrientes, los que nos quieren decir por dónde va el arte contemporáneo, según cierto "caleidoscopio internacional", y los que miran las imágenes y su significado.

\section{¿Podrías explicar con detalle tu técnica como retratista?}

Creo en lo que una vez dijo Edward Steichen, que un solo retrato es incapaz de registrar todas las expresiones vitales de una persona, es decir, desde la alegría plena hasta la tristeza más profunda. Sin embargo, si uno es capaz de capturar un momento, uno solo, que pueda ser asociado con la naturaleza íntima o adjudicable al retratado, uno debe darse por satisfecho, porque no va a poder lograr más que eso.

En términos más prácticos, lo primero es la dirección de la luz natural, porque trato de no usar luz artificial. Lo segundo es el entorno, porque lo que rodea a tu sujeto se vuelve parte del retrato. Cuando descubrí lo que llamo el espacio negativo, que lo que rodea al personaje en la toma es también una forma, una estructura que va a ser tan importante como el retratado. Este espacio va a enmarcar, a soportar, a darle contraste y volumen al personaje fotografiado. Ese espacio puede estar poblado o despoblado, puede tener elementos que se relacionen con el personaje o simplemente para darle carácter. Y he aquí lo más importante: una vez que la luz y los elementos que lo rodean estén compuestos en el visor, se debe saber esperar a que el personaje nos entregue, regale, atisbe, un guiño, un queco, un rasgo personal propio y singular del universo que puede ser la persona fotografiada. 


\section{¿Qué es más importante en tus retratos, tu mirada o la del personaje?}

Creo que lo que vemos a través del visor es al personaje. Todo lo que transcurre hasta el momento de disparar es parte de una técnica que uno va construyendo internamente, casi sin pensarlo, como en automático. Me gusta que, cuando uno ve una foto mía lograda, vea al personaje con nitidez.

La sensación que uno tiene cuando una de las fotos que uno ha tomado se vuelve el retratado. No una foto de, sino el personaje mismo. Ese es un aspecto del trabajo importante porque implica una responsabilidad de enorme peso, y es que el trabajo no termina cuando uno hace la foto. Porque en este trabajo de capturar una fracción del tiempo, lo que uno puede lograr es también la eternidad.

\section{¿Qué proyectos estás trabajando ahora?}

Rescate de archivos fotográficos. Investigar y redescubrir. La labor de un comunicador no es solo la de producir las imágenes, sino también ponerlas en valor, y en este país de desmemoriados y amnésicos un poco de evocación siempre es saludable. 
DOSIER FOTOGRÁFICO / HERMAN SCHWARZ

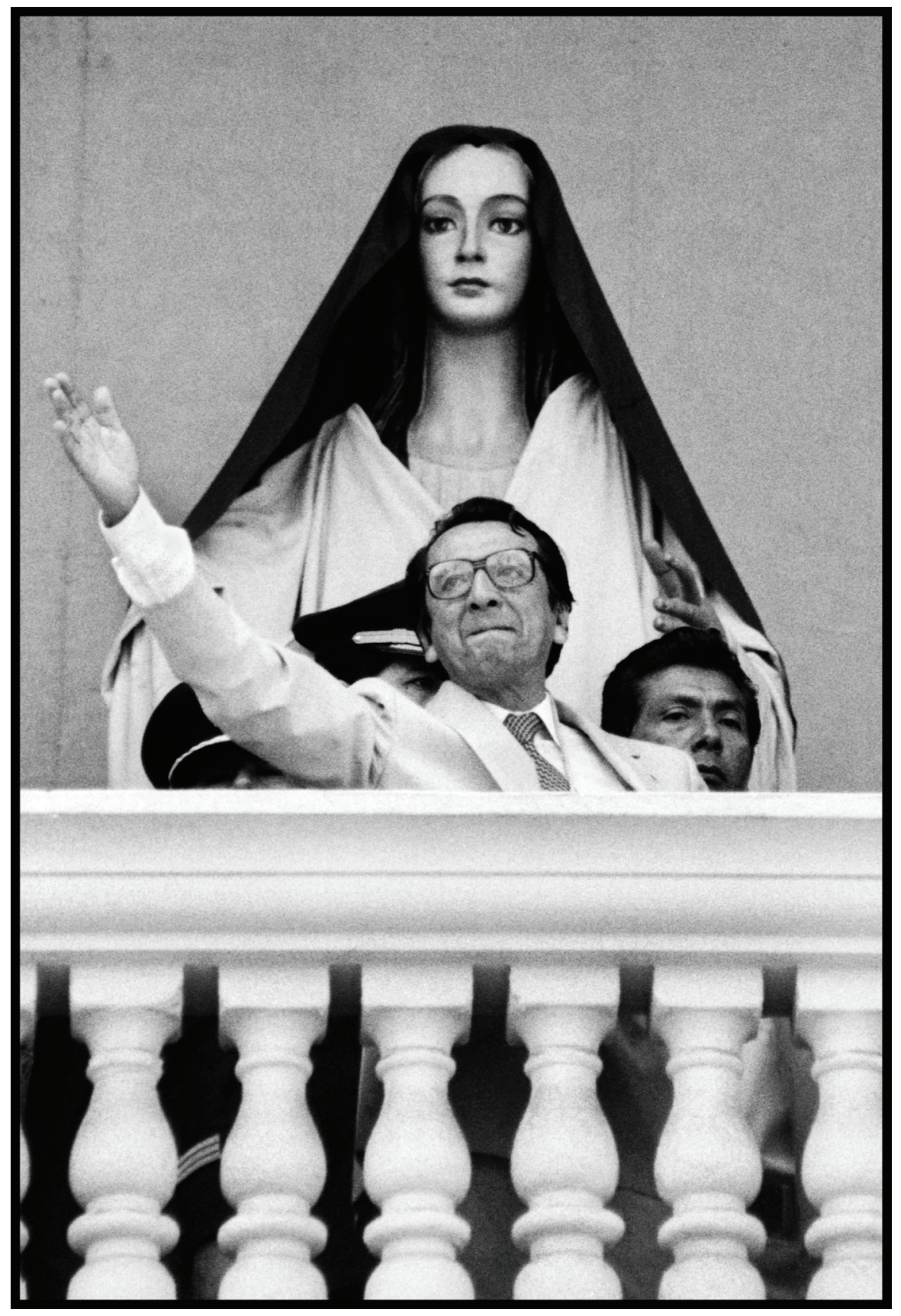

Alfonso Barrantes (Lima, 1984) 


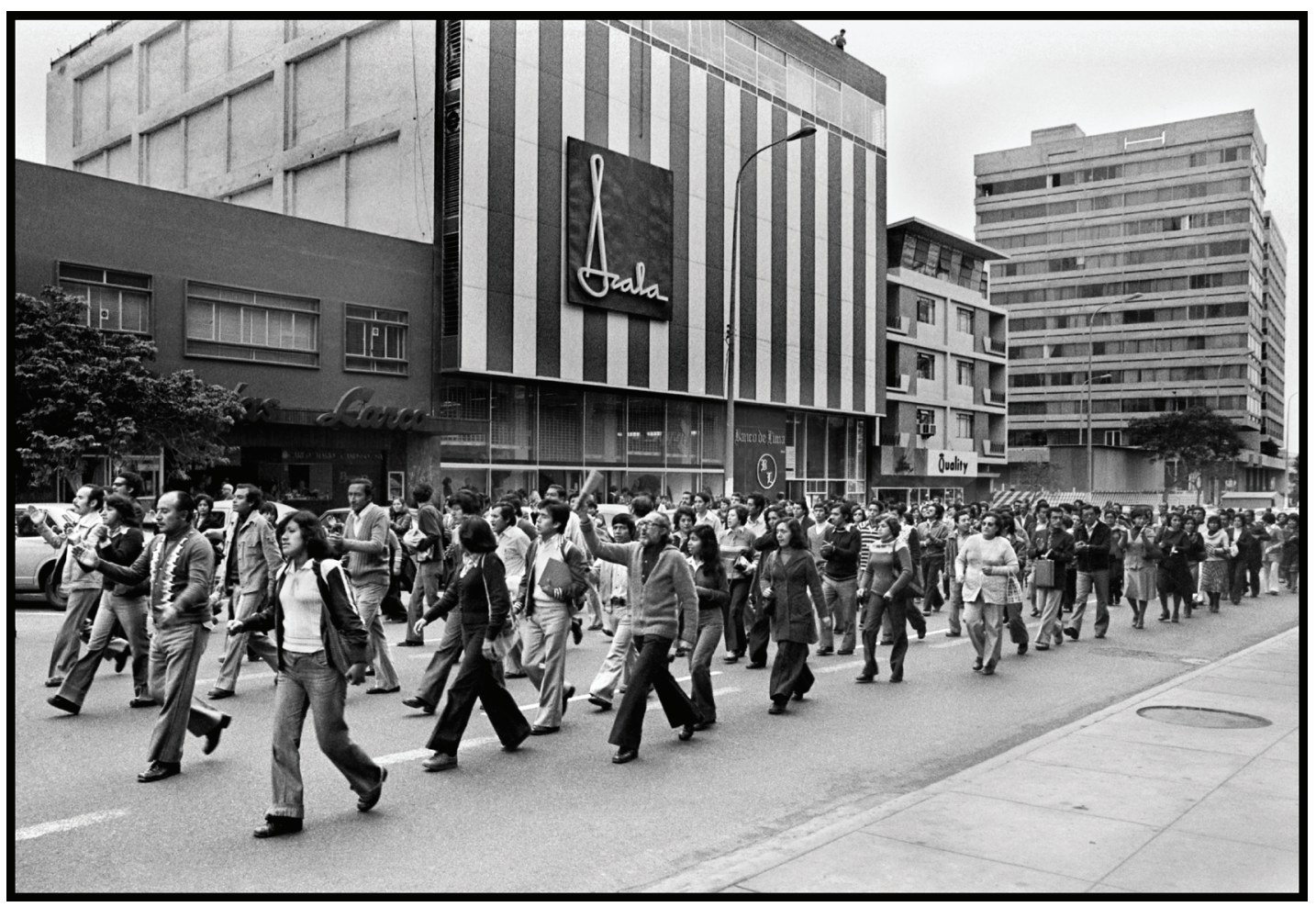

Maestros en la avenida Larco (Miraflores, 1979) 


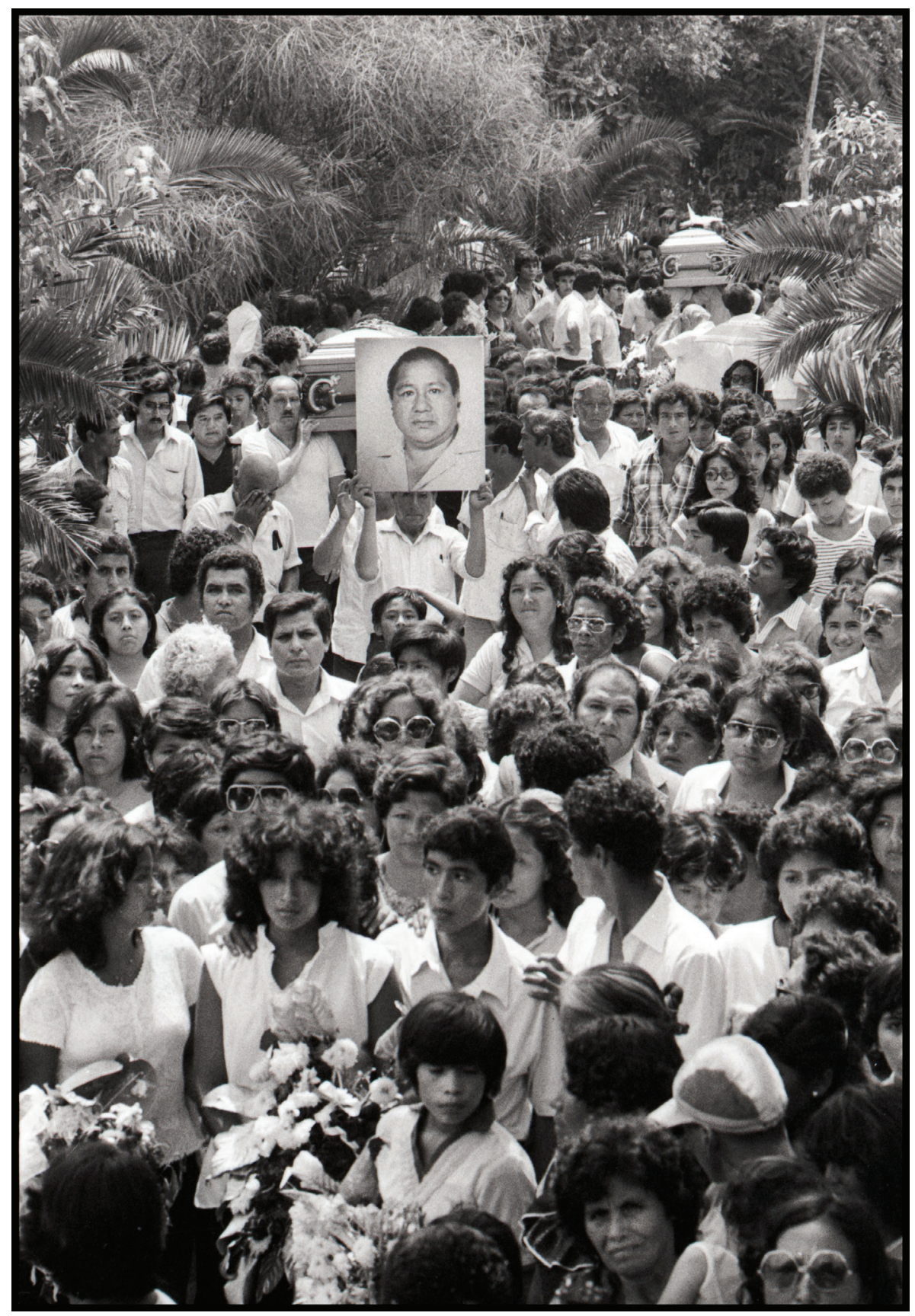

Uchuraccay. Jorge Sedano (cementerio El Ángel, 1983) 


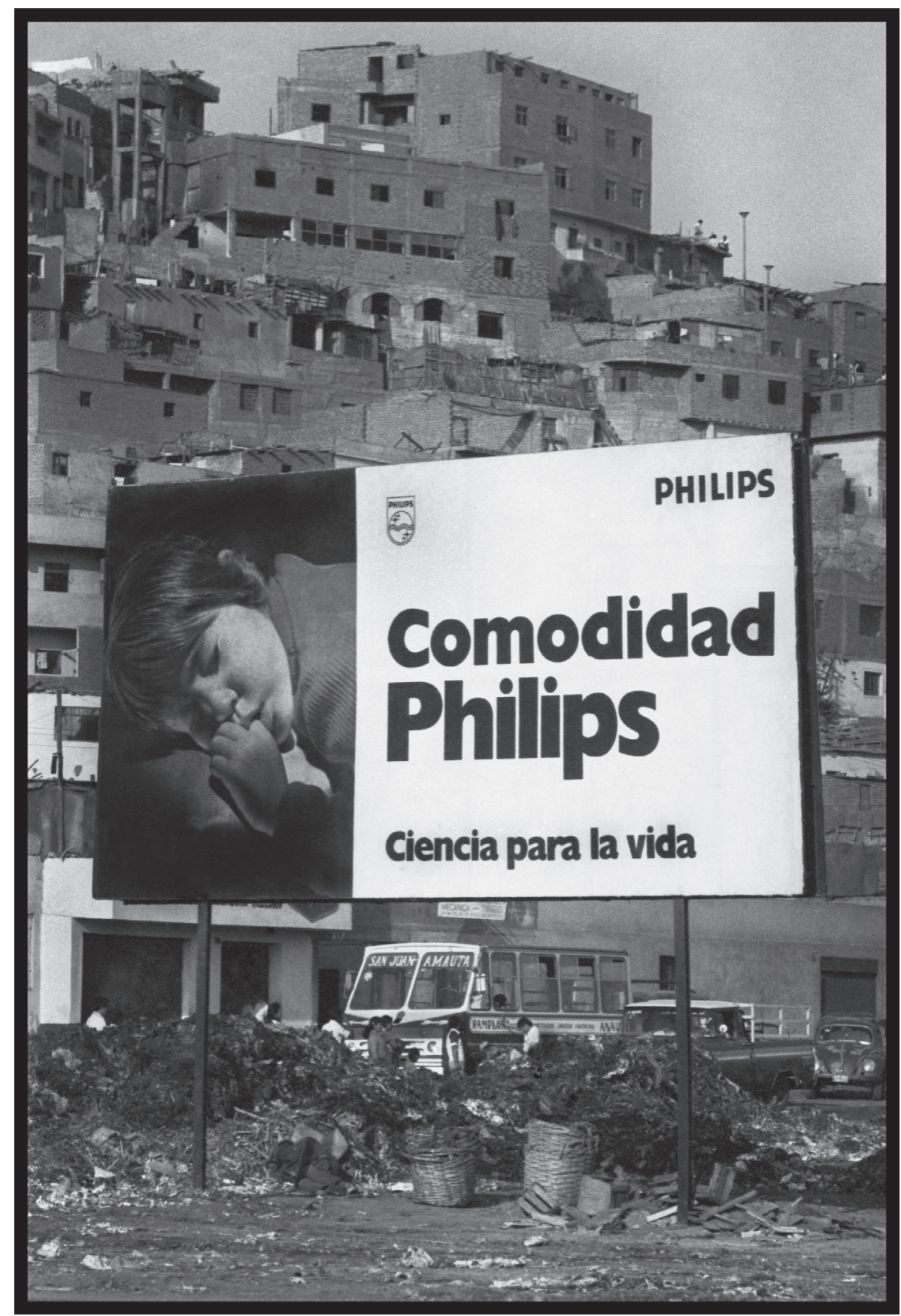

Comodidad (La Victoria, 1981) 


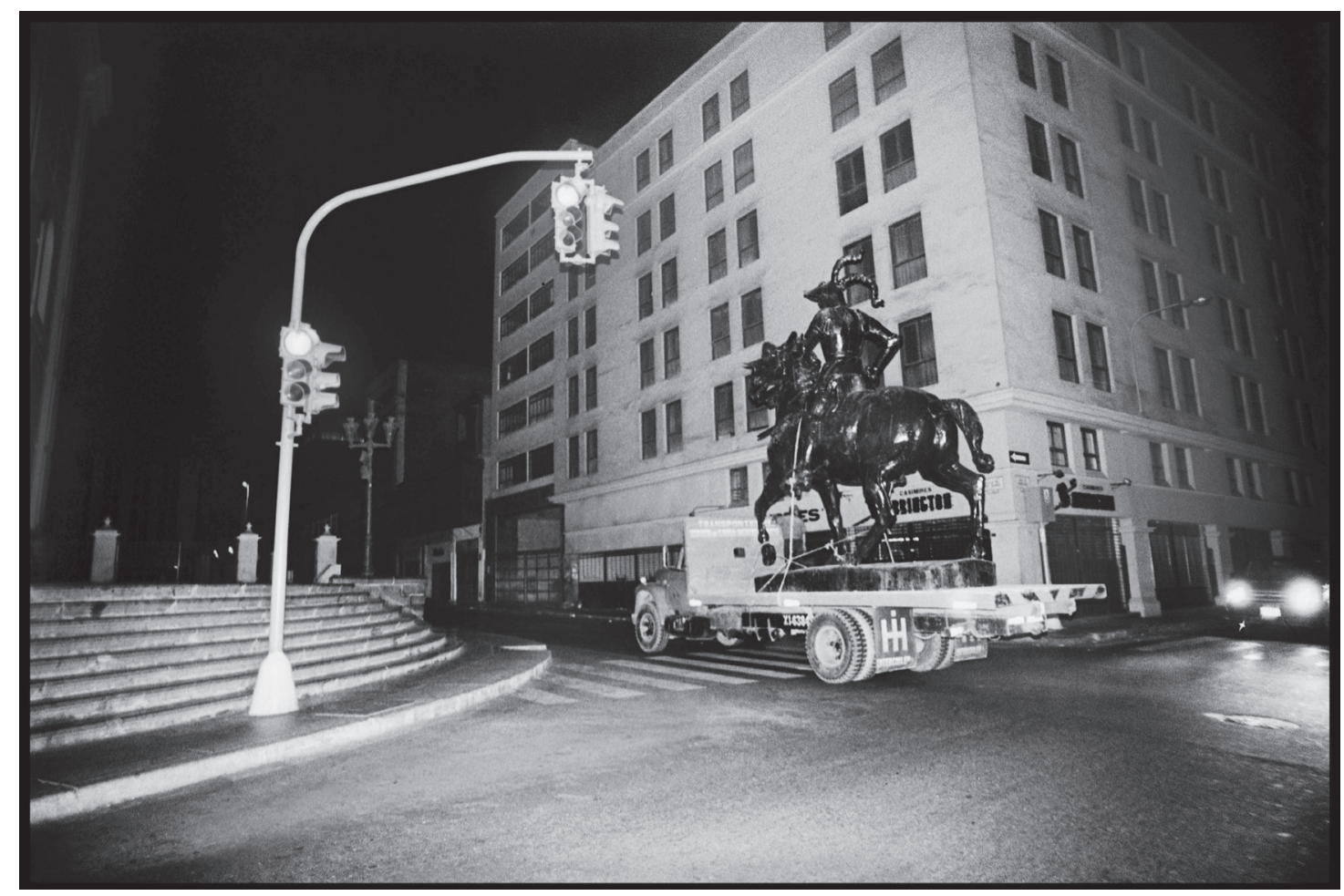

Chau, Pizarro (Plaza de Armas de Lima, 2003) 


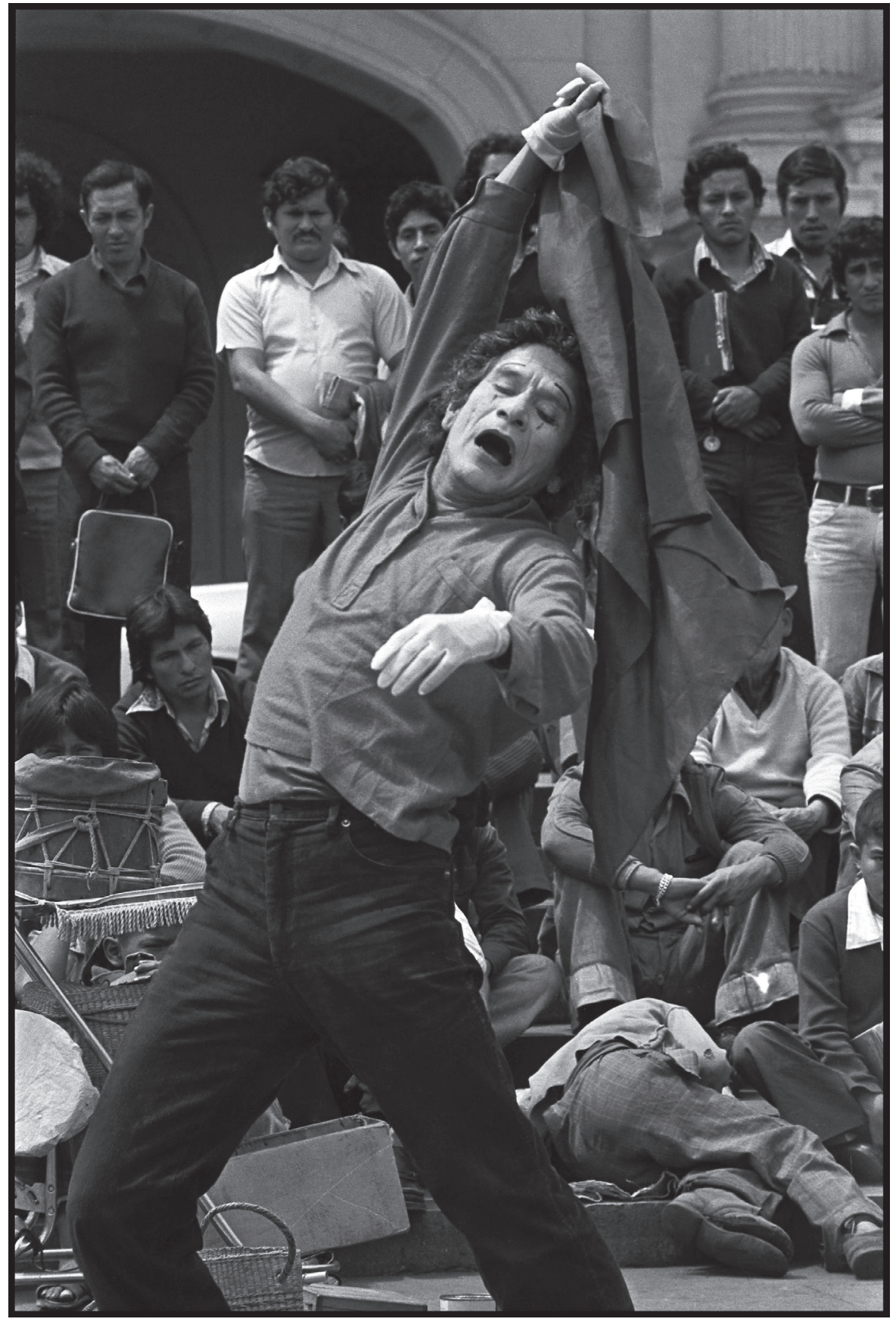

Jorge Acuña. La madre de Brecht 1 (Plaza San Martín, 1997) 


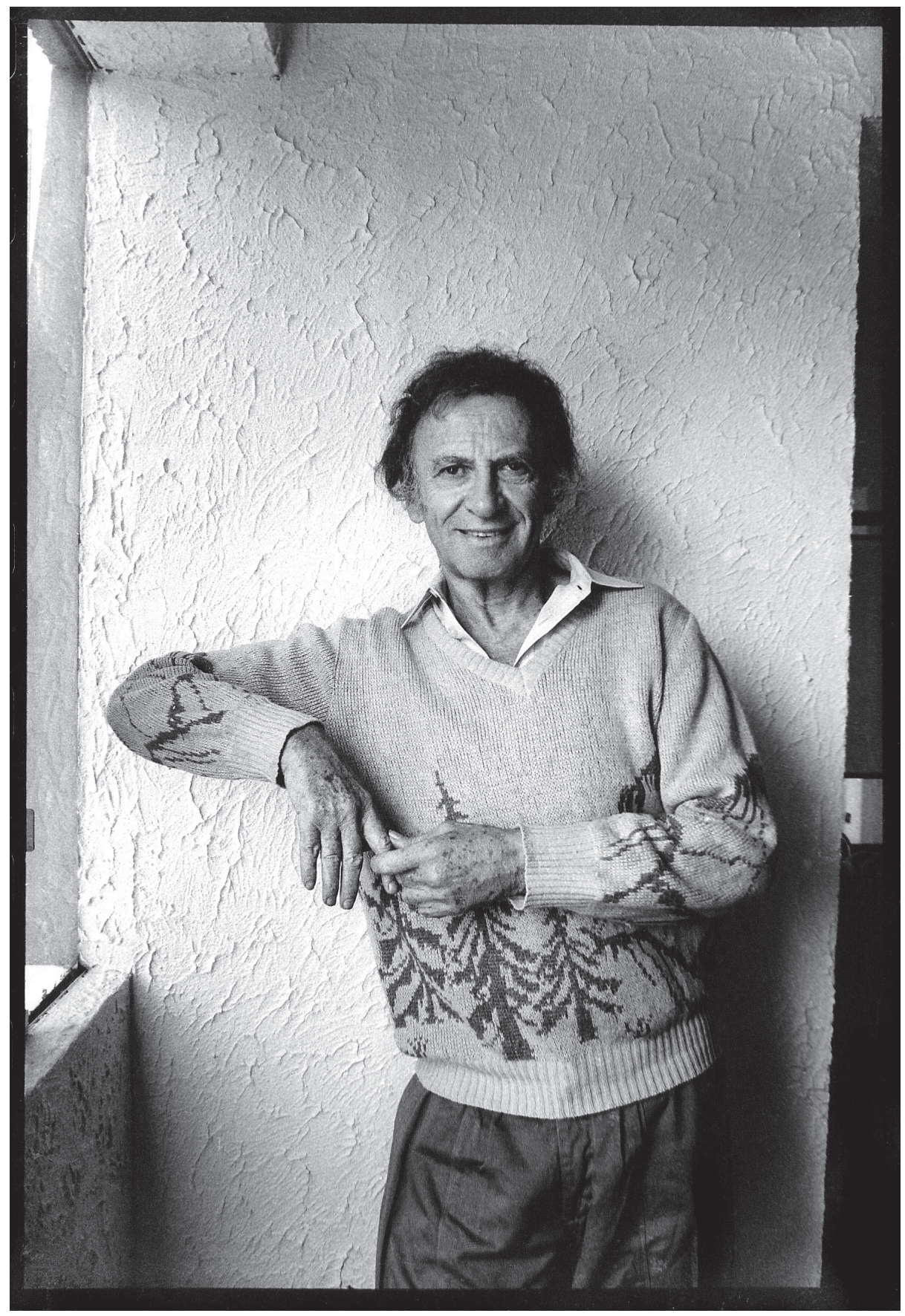

Marcel Marceau, mimo (Miraflores, 1987) 


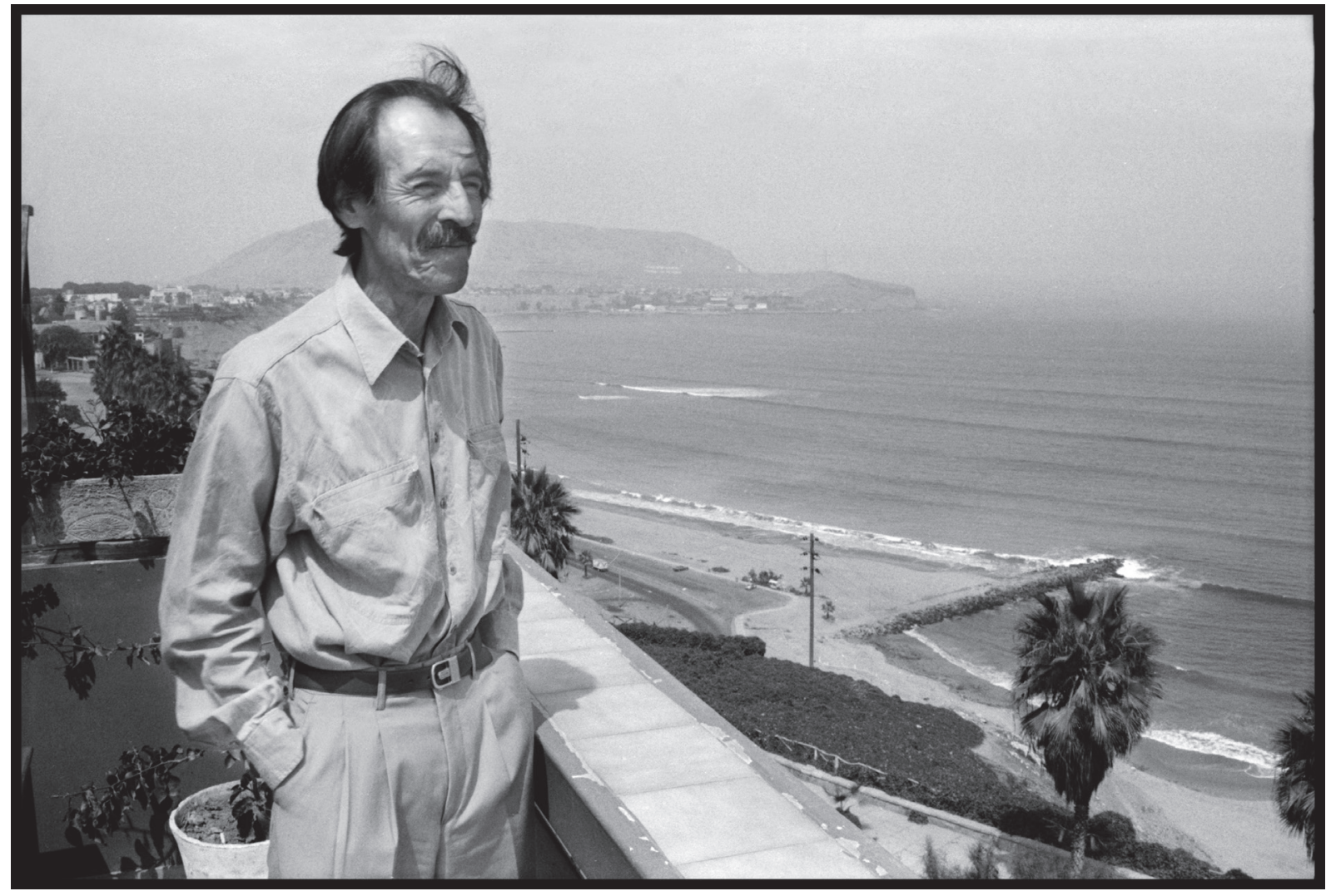

Julio Ramón Ribeyro (Barranco, 1994) 


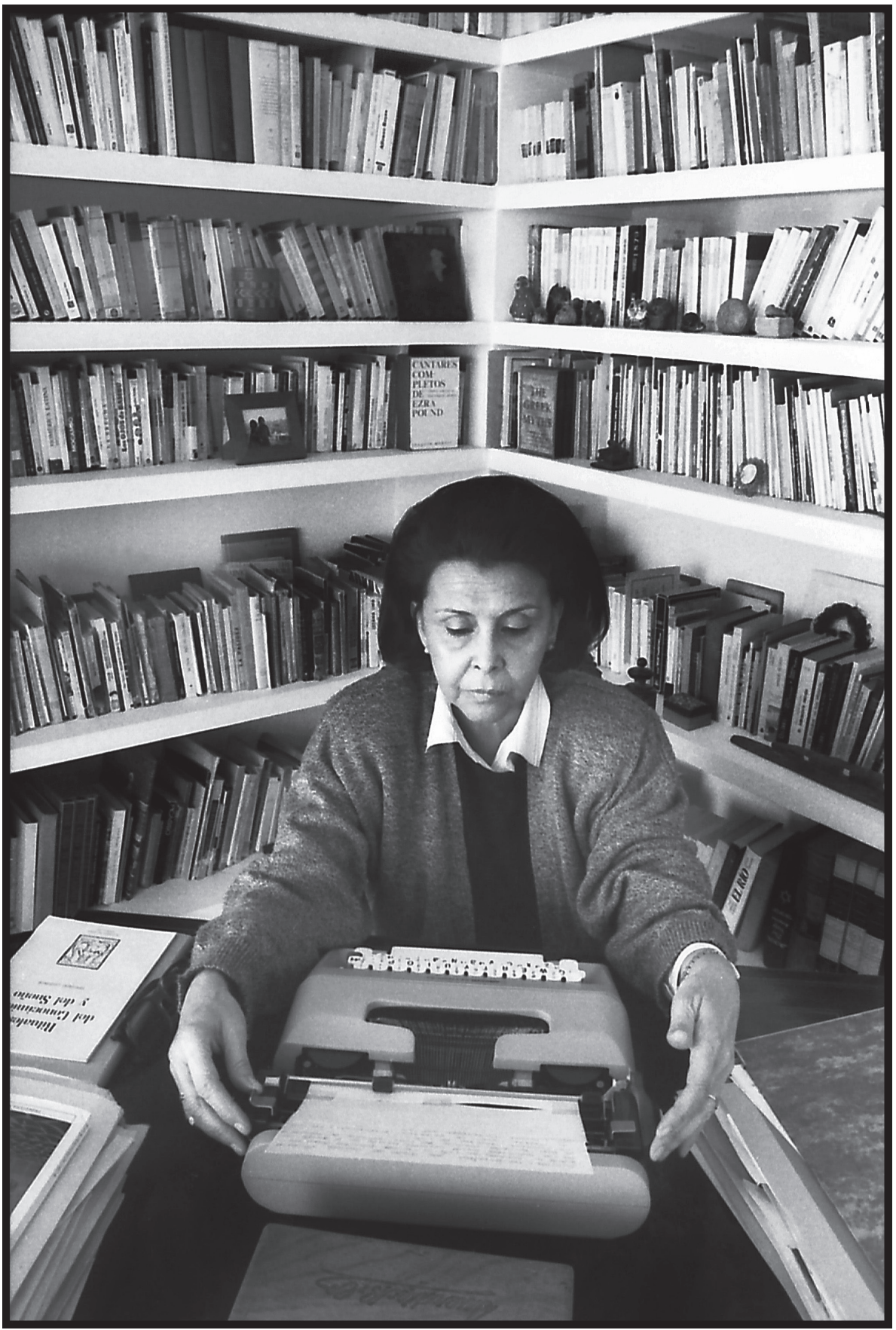

Blanca Varela en su estudio (Barranco, 1988) 


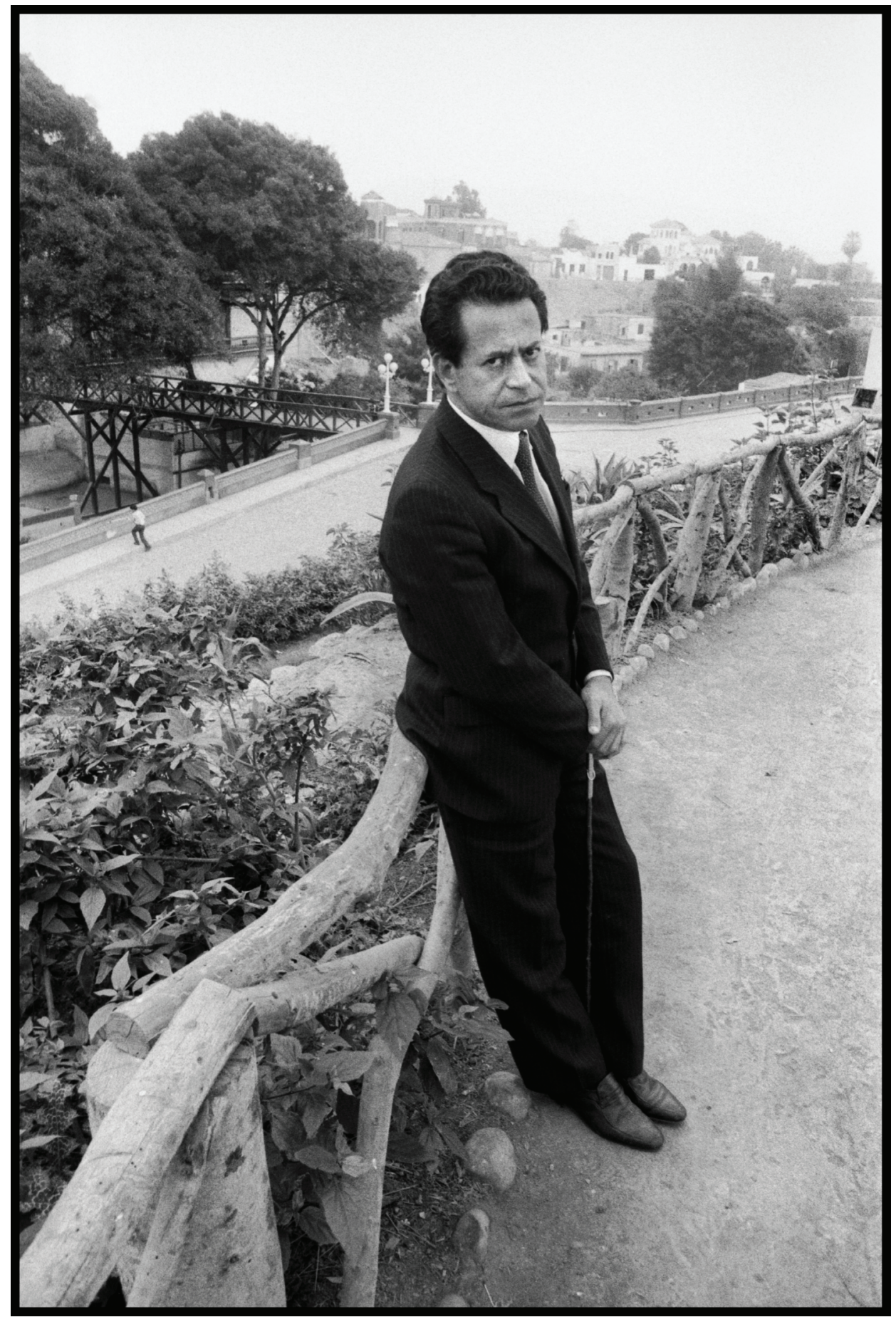

César Calvo, poeta (Barranco, 1986) 


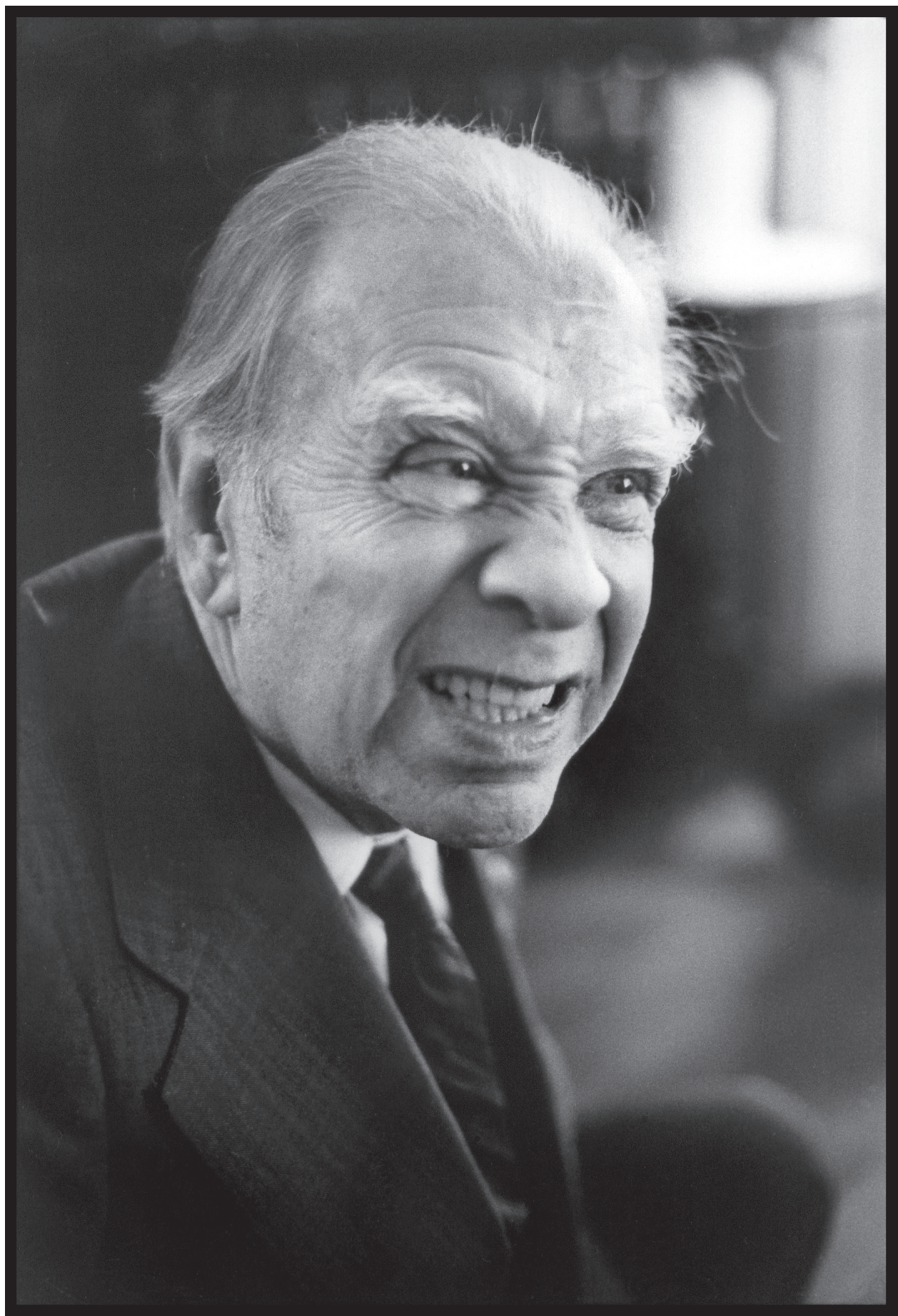

Jorge Luis Borges (Buenos Aires, 1981) 


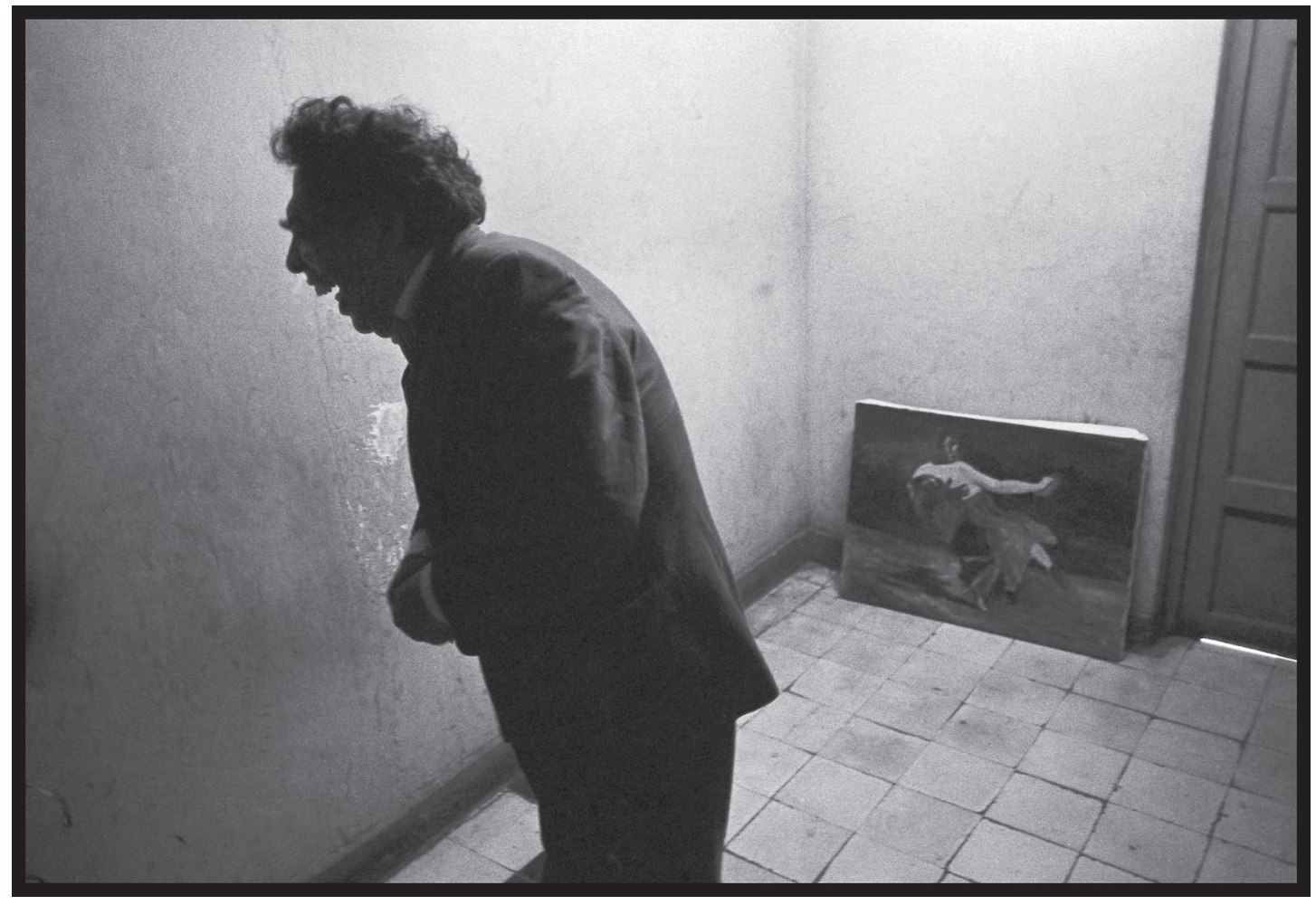

Víctor Humareda, pintor genial (Lima, 1982) 